\title{
Wire Fox Terrier
}

National Cancer Institute

\section{Source}

National Cancer Institute. Wire Fox Terrier. NCI Thesaurus. Code C53718.

The Wirehaired Fox Terrier is a small, strong dog with a wiry coat with black or brown markings. The breed has a flat, tapering, narrow skull, and ears that fold forward making "V" shaped flaps. Height: 13-16 inches (33-41 cm.) Weight: 13-20 pounds (6-9 kg.) 